\section{Key Words}

carbazoles carbon monoxide cyclization

J. H. SMITROVICH,* I. W. DAVIES (MERCK \& CO., INC., NEW JERSEY, USA)

Catalytic C-H Functionalization Driven by CO as A Stoichiometric Reductant: Application to Carbazole Synthesis Org. Lett. 2004, 6, 533-535.

\title{
Catalytic C-H Functionalization Driven by CO as a Stoichiometric Reductant - Application to Carbazole Synthesis
}

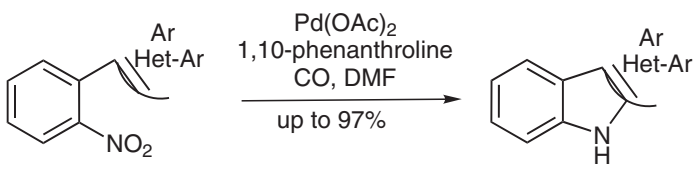

Significance: A general synthetic method for carbazole, thieno[2,3-b]indole and 9H-Pyrido[2,3$b$ ]indoles by palladium-catalyzed CO-mediated reductive cyclization of 2-nitro biaryls compounds is reported. The reactions proceed in excelled yields under mild conditions. Comprehensive screening of conditions shows that conversion is increased with increasing temperature and pressure, with optimal conditions being 70 psi of $\mathrm{CO}$ and $140{ }^{\circ} \mathrm{C}$ in DMF utilizing $2 \mathrm{~mol} \%$ of $\mathrm{Pd}(\mathrm{OAc})_{2}$ and $4 \mathrm{~mol} \%$ of ligand (1,10-phenanthroline). A broad range of heterocycles has been prepared by this method.
Comment: The synthesized heterocycles constitute important frameworks in material science and pharmaceuticals. In particular, substituted carbazoles play an important role in the development of conducting and ferromagnetic polymers. The present catalytic procedure is an inexpensive and general method for the preparation of polysubstituted carbazole in multigrams scale. 